\title{
Intimate partner violence in older South African women: An analysis of the 2016 Demographic and Health Survey
}

\author{
N Metheny, ${ }^{1} \mathrm{PhD}, \mathrm{MPH}, \mathrm{RN} ; \mathrm{Z}$ Essack, ${ }^{2,3} \mathrm{PhD}$ \\ ${ }^{1}$ MAP Centre for Urban Health Solutions, St Michael's Hospital, Toronto, Canada; and School of Nursing and Health Studies, \\ University of Miami, Coral Gables, USA \\ ${ }^{2}$ Human Sciences Research Council, Pietermaritzburg, South Africa \\ ${ }^{3}$ School of Law, University of KwaZulu-Natal, Pietermaritzburg, South Africa
}

Corresponding author: N Metheny (nick.metheny@unityhealth.to)

\begin{abstract}
Background. South Africa (SA) has one of the highest rates of intimate partner violence (IPV) in the world. It is also in the midst of a demographic transition in which the number of people aged $>60$ years is expected to double by mid-century. Despite the confluence of these two public health issues, there are no published studies on the epidemiology and risk factors for IPV in older SA women.

Objectives. To provide a foundational understanding of IPV among women aged $\geq 50$ years in SA.

Methods. This study used the first-ever nationally representative sample of women aged $>49(N=2265)$ that includes data on physical, sexual, and emotional IPV. Both lifetime experience of IPV and IPV within the past 12 months were reported, as was the presence of controlling behaviours by the partner. Four multilevel logistic models and one multilevel linear regression model were fit to examine the demographic, developmental and structural correlates of IPV in women aged 50 - 95.

Results. The lifetime prevalence rates for all types of IPV were slightly higher among older women than among women aged 15 - 49. Nine percent of respondents reported IPV in the past 12 months, and 35\% reported at least one persistent controlling behaviour. Divorced/ separated women and those who had witnessed IPV as a child had greater odds of reporting IPV. In contrast to the literature on younger women, education, race and wealth were not strong predictors of IPV in this sample of older women.

Conclusions. This study is the first of its kind in the SA context, and shows that IPV is a persistent threat for women across the lifespan. It suggests that IPV may manifest differently in older women compared with women of reproductive age, necessitating future qualitative and quantitative studies that examine the correlates, causes and points of intervention unique to this growing population.
\end{abstract}

S Afr Med J 2020;110(10):1020-1025. https://doi.org/10.7196/SAMJ.2020.v110i10.14684

Intimate partner violence (IPV) is a major global health concern, with more than one-third of women worldwide reporting lifetime experience of physical or sexual IPV. ${ }^{[1]}$ Defined as 'any behaviour within an intimate relationship that causes physical, psychological or sexual harm to those in the relationship, ${ }^{[1]}$ IPV includes acts of physical and sexual violence, emotional/psychological abuse, and controlling behaviours or coercive control. While this definition does not delineate any age-related exclusions, the broader IPV discourse, research, policy and support services have so far focused on IPV in women of reproductive age (15 - 49 years). ${ }^{[2,3]}$ This limitation has not adequately recognised the long-term effects on the health and wellbeing of older women who experience IPV earlier or later in life. ${ }^{[3,4]}$ It is important to distinguish between IPV perpetrated against an elder and elder abuse, the latter being defined as 'a single, or repeated act, or lack of appropriate action, occurring within any relationship where there is an expectation of trust, which causes harm or distress to an older person. ${ }^{\text {?[] }}$ This means that elder abuse can be perpetrated by non-intimate individuals as well as those who are in an intimate relationship with the victim.

Recent work has begun to include IPV experiences of older women, although it has almost universally taken place in developedcountry contexts. ${ }^{[6]}$ Data from the USA suggest that the prevalence of physical IPV declines as women get older, but non-physical types of IPV are similar across the lifespan, ${ }^{[6,7]}$ supporting findings from the USA and Canada that the prevalence of emotional/ psychological abuse is higher than that of physical or sexual abuse for older women (defined as age $>50$ ) ${ }^{[8,9]}$ A recent narrative review of IPV among older women reported that IPV is common but that their age and life transitions may beget experiences dissimilar to those of younger women. ${ }^{[6]}$ A systematic review of risk and protective factors for IPV among older women, largely in North America and East Asia, identified social support, help-seeking behaviour, and the availability of services to address IPV as primary protective factors. ${ }^{[10]}$ Factors perpetuating risk included economic circumstances, ethnic minority status, cognitive or physical impairment, relational dynamics and other conditions associated with cultural background. ${ }^{[10]}$ Older women appear less inclined to seek external (sometimes referred to as formal) support to deal with IPV and less likely to leave their abusive partners than younger women. ${ }^{[1,12]}$ Failure to seek external support has been linked to a lack of awareness of support, ${ }^{[6]}$ finances, employment, housing and healthcare, ${ }^{[13]}$ as well as traditional gender roles, cultural norms and women's emotions and perceptions. ${ }^{[14]}$ Considering that only one study from both these reviews came from outside developedcountry contexts and none was from Africa, additional inquiry into how IPV is manifested, and how IPV experienced earlier in life is associated with health outcomes as an elder, is warranted, especially in low- to middle-income countries (LMICs).

South Africa (SA) has one of the world's highest rates of IPV, with $20-50 \%$ of adult women reporting experiencing IPV in their lifetime. ${ }^{[15,16]}$ The macrosocial forces driving violence - gender inequality chief among them ${ }^{[17]}$ - affect women of all ages. Recent highly publicised and alarming incidents of gender-based violence (GBV), which includes IPV, and femicide in SA resulted in President 
Cyril Ramaphosa's announcement of a five-point emergency plan to address GBV in the country. ${ }^{[18,19]}$

$\mathrm{SA}$ is also in the midst of a demographic and epidemiological transition, with decreases in fertility rates reducing the number of young people relative to the general population and the advent of public health policies and medical advances, such as highly active antiretroviral therapy for HIV, improving life expectancy. ${ }^{[5,20]}$ By 2025 , the proportion of South Africans aged $>60$ is expected to grow by $189 \%$ over 1985 levels, ${ }^{[20]}$ and the overall number of older South Africans is expected to double by $2050 \cdot{ }^{[5]}$ Coupled with the high rates of IPV and a national priority to address it, analysis of how IPV is experienced by this growing population is sorely needed.

\section{Objectives}

To our knowledge, the present analysis is the first attempt at exploring IPV in older women in SA, and it aims to begin filling the void in the literature regarding IPV among older women in LMICs. Using data from a nationally representative SA survey ${ }^{[21]}$ to explore the prevalence and risk factors of different forms of IPV among women aged $\geq 50$ years, we sought to capitalise on the first representative sample of IPV among older women in the country. Understanding the experience of IPV for older women in SA is a critical precursor to designing interventions and policies that align with the government's plan to break the cycle of violence and reduce the negative health and social implications of IPV.

\section{Methods}

Data for this analysis were drawn from the women's questionnaire of the 2016 South African Demographic and Health Survey (DHS) $(N=11497) .^{[21]}$ Using a two-stage sampling design, the DHS utilises the sampling frame from the most recent census data to create geographical demarcations called primary sampling units (PSUs) consisting of 100 - 300 households. DHS interviewers then collect data from eligible women in a random sample of 20 - 30 of these households. ${ }^{[22]}$ Of these, $\sim 60 \%$ are also selected to complete the Domestic Violence Module. ${ }^{[23]}$ Historically, only women of reproductive age (15 - 49 years) were interviewed for both the main survey and the Domestic Violence Module. In the 2016 survey, however, all women aged $\geq 18$ were eligible for completion of the Domestic Violence Module. While the main survey contains data from women of reproductive age only ( $N=9235)$, the 2016 South Africa DHS Domestic Violence Module is therefore the first of its kind to include responses from women aged 50 - 95 ( $N=2265)$. This subsample of women aged $\geq 50$ constitutes the analysis sample for this study.

\section{Outcomes}

Three outcome variables measured reported lifetime prevalence of three types of IPV and were coded 1 if the respondent indicated that her husband or male partner had ever committed physical violence (pushed, shook, or threw something; slapped, punched, or kicked; attempted to strangle or burn her; twisted her arm or pulled her hair; or threatened her with a knife or gun), sexual violence (partner physically forced sex when not wanted; ever forced other sexual acts when not wanted) or emotional violence (humiliated in public, threatened harm, insulted her or made her feel bad) against her after the age of 15 years. A continuous measure of coercive control was created via a summative scale (range $0-4$ ) of the number of controlling behaviours (e.g. 'Does your husband/partner get jealous if you talk to other men?', 'Does your husband/partner prevent you from meeting with your female friends?') reported by women.
Although the questions are phrased in present tense, all women were asked these questions, regardless of current marital status. A fifth outcome measured whether a respondent had experienced physical, sexual or emotional IPV in the past 12 months.

\section{Key covariates}

Owing to the lack of published data on IPV in older women residing in LMICs, demographic variables are considered key covariates in this descriptive study. Age: The respondent's age was collapsed into 5-year increments $(50-55,56-60,61-65,66-70,71-75$ and $\geq 76)$. Race: Self-identified ethnicity was coded using the original SA census options and collapsed into three categories: black African, white, and coloured/Indian/other. Level of education: Respondents' level of education was captured in a three-level ordinal variable: less than primary school, completion of primary school, or completion of secondary school or more advanced education. Marital status: Women were coded as never married, currently married/cohabiting with a male partner, widowed, or divorced/separated. Wealth quintile: Respondents were categorised into wealth quintiles from 1 (poorest) to 5 (richest), using the DHS asset-based algorithm. ${ }^{[2]}$ Controlling behaviour: The IPV literature has consistently shown that coercive control is a separate form of IPV ${ }^{[1]}$ that commonly precedes and co-occurs with other forms of IPV. ${ }^{[25,26]}$ To understand older women's experiences with controlling behaviour and its association with other forms of violence, a dichotomous variable was created if a respondent reported experiencing one or more forms of coercive control. This variable was included in all models except for the one in which controlling behaviour is the outcome variable. Information and communication: Previous studies have found links between younger women's use of information and communication devices (i.e. television, radio, newspaper, mobile phone) and attitudes toward IPV, independent of household wealth and other sociodemographic factors. ${ }^{[27,28]}$ To better understand whether the benefits of information and communication use extend to older women (who may use them less often), respondents were coded 1 if they reported television, radio, or internet use at least weekly and also if they owned a mobile phone. Responses were combined into a summative scale (range 0 - 4) to gauge information and communication connectivity. Finally, social learning theory posits that witnessing IPV as a child leads to an internalisation of strict gender norms and violence as an acceptable way to manage conflict. ${ }^{[2,30]}$ However, nearly all literature on this theory concerns younger women, whose experiences of IPV may be more proximal to witnessing the parental violence. To understand whether experiences of witnessing their father perpetrate physical violence against their mother as a child is associated with older women's lifetime and recent experiences of IPV as adults, a dichotomous variable was created and coded 1 if women reported witnessing parental IPV.

\section{Analyses}

The nesting of respondents within communities (PSUs) necessitates the use of multilevel modelling in these analyses. ${ }^{[31-33]}$ Compared with standard logistic regression analyses, multilevel modelling corrects for the downward bias in standard errors created by the non-independent nature of nested data and introduces an error term that captures the effects of unobserved covariates. ${ }^{[31,34]} \mathrm{A}$ total of five multilevel logistic regression models were fit using this approach, with PSU as a random intercept. Models included one each for lifetime exposure to physical, sexual or emotional IPV, a fourth for coercive control, and a fifth for experience of physical, sexual or emotional IPV in the past 12 months. 


\section{Results}

Respondents were more or less evenly distributed across SA, with the largest proportion $(16.6 \% ; n=376)$ living in Limpopo Province and $40.7 \%$ ( $n=1124$ ) living in rural areas. The mean (standard deviation) age was $63.91(10.27)$ years, and $78.0 \%(n=1174)$ identified as black African, roughly reflecting the country's racial demography. More than $15 \%$ of respondents $(n=299)$ reported experiencing physical IPV in their lifetime, while $4.6 \%(n=89)$ reported sexual IPV and nearly one in five $(19.7 \% ; n=379)$ reported emotional IPV. More than one in three $(35.2 \% ; n=679)$ reported at least one form of coercive control and $9.0 \%(n=173)$ reported physical, sexual or emotional IPV in the past 12 months. Nearly $12 \%(11.5 \% ; n=259)$ reported witnessing their father perpetrate physical IPV against their mother as a child, on par with women of reproductive age in the same sample (14.1\%). Full descriptive statistics are shown in Table 1.

Results of the multilevel logistic and linear regression analyses depart from the conventional wisdom surrounding correlates of IPV in women of reproductive age. With the exception of coercive control, age was not significantly associated with lifetime experience of IPV. Compared with women aged 50 - 55 years, those aged 71 $75(\beta=-0.27$ (95\% confidence interval (CI) $-0.50--0.04)$; $p<0.05)$ and $\geq 76(\beta=-0.22(95 \%$ CI $-0.44--0.01) ; p<0.05)$ were less likely to report experiencing coercive control. Age was associated with recent IPV, however, with women aged 56 - 60 (odds ratio (OR) 0.52 (95\% CI 0.32 - 0.85); $p<0.01$ ), 66 - 70 (OR 0.51 (95\% CI 0.28 - 0.93); $p<0.05$ ), and $\geq 76$ (OR 0.32 (95\% CI $0.15-0.69$ ); $p<0.01$ ) all having a significantly lower odds of experiencing IPV than those aged 50 55. Level of education was associated with lifetime experience of coercive control, with women who had completed primary $(\beta=0.25$ (95\% CI 0.08 - 0.42); $p<0.01)$ and secondary $(\beta=0.22(95 \%$ CI 0.03 $0.41) ; p<0.05)$ school significantly more likely to report controlling behaviour than women who had not completed primary school. Interestingly, race was also significantly associated with lifetime report of coercive control only. Compared with black women, white women $(\beta=-0.62$ (95\% CI $-0.88-0.37) ; p<0.01)$ and coloured/ Indian/other women $(\beta=-0.30$ (95\% CI $-0.51--0.08) ; p<0.01)$ were significantly less likely to report controlling behaviour. While currently married women were significantly less likely to report lifetime experience of coercive control than women who had never been married $(\beta=-0.31$ (95\% CI $-0.53--0.09) ; p<0.01)$, they had nearly twice the odds of reporting physical, sexual or emotional IPV in the past 12 months (OR 1.92 (95\% CI 1.07 - 3.45); $p<0.05$ ). Divorced or separated women had much greater odds of reporting lifetime physical (OR 3.00 (95\% CI 1.67 - 5.38); $p<0.001$ ), sexual (OR 2.69 (95\% CI 1.07 - 6.74); $p<0.05)$ and emotional (OR $3.26(95 \%$ CI $1.89-5.64) ; p<0.001) \mathrm{IPV}$, as well as controlling behaviour $(\beta=0.45$ (95\% CI $0.18-0.72) ; p<0.001)$, but not recent IPV. Wealth was not a major correlate of IPV in this sample, but women in the richest quintile reported significantly less coercive control over their lifetimes than women in the poorest quintile $(\beta=-0.40(95 \% \mathrm{CI}-0.70--0.10)$; $p<0.01)$. Greater connectivity through mobile phones, internet, telephone or radio was significantly associated with reporting more coercive control $(\beta=0.13$ (95\% CI $0.06-0.20) ; p<0.001)$. Witnessing parental physical IPV was associated with significantly greater odds of lifetime physical (OR 1.66 (95\% CI $1.15-2.39$ ); $p<0.01$ ), sexual (OR 2.06 (95\% CI $1.24-3.42) ; p<0.01$ ) and emotional (OR $1.82(95 \%$ CI 1.30 - 2.56); $p<0.001)$ IPV, as well as more coercive control $(\beta=0.69$ ( $95 \%$ CI $0.51-0.88) ; p<0.001$ ). The presence of controlling behaviour in a relationship was significantly associated with much greater odds of reporting lifetime (physical OR 10.36 (95\% CI 7.40 - 14.50);
Table 1. Sample characteristics and prevalence of IPV $(N=2265)$

\begin{tabular}{|c|c|}
\hline Indicator & \\
\hline Age (years), mean SD & $63.91(10.27)$ \\
\hline \multicolumn{2}{|l|}{ Province of residence, $n(\%)$} \\
\hline Western Cape & $184(8.1)$ \\
\hline Eastern Cape & $370(16.4)$ \\
\hline Northern Cape & $224(9.9)$ \\
\hline Free State & $251(11.1)$ \\
\hline KwaZulu-Natal & $328(14.5)$ \\
\hline North West & $207(9.2)$ \\
\hline Gauteng & $136(6.0)$ \\
\hline Mpumalanga & $186(8.2)$ \\
\hline Limpopo & $376(16.6)$ \\
\hline Rural, $n(\%)$ & $1124(40.7)$ \\
\hline \multicolumn{2}{|l|}{ Education, $n(\%)$} \\
\hline No education & $567(25.1)$ \\
\hline Primary education & $722(31.9)$ \\
\hline Secondary or higher education & $973(43.0)$ \\
\hline \multicolumn{2}{|l|}{ Race, $n(\%)$} \\
\hline Black African & $1764(78.0)$ \\
\hline White & $229(10.1)$ \\
\hline Coloured/Indian/other & $269(11.9)$ \\
\hline \multicolumn{2}{|l|}{ Wealth quintile, $n$ (\%) } \\
\hline Poorest & $474(21.0)$ \\
\hline Poorer & $451(19.9)$ \\
\hline Middle & $424(18.7)$ \\
\hline Higher & $428(18.9)$ \\
\hline Highest & $485(21.4)$ \\
\hline \multicolumn{2}{|l|}{ Marital status, $n(\%)$} \\
\hline Never in union & $513(22.7)$ \\
\hline Married/cohabiting & $862(38.1)$ \\
\hline Widowed & $695(30.7)$ \\
\hline Divorced/separated & $192(8.5)$ \\
\hline Currently employed, $n(\%)$ & $495(21.9)$ \\
\hline \multicolumn{2}{|l|}{ Connectivity, $n$ (\%) } \\
\hline Internet - access at least weekly & $218(9.6)$ \\
\hline Radio - listens at least weekly & $1146(50.7)$ \\
\hline Television - watches at least weekly & $1452(64.2)$ \\
\hline Owns mobile phone & $1832(81.0)$ \\
\hline \multicolumn{2}{|l|}{ Lifetime experience of IPV, $n(\%)$} \\
\hline Emotional violence & $379(19.7)$ \\
\hline Sexual violence & $89(4.6)$ \\
\hline Physical violence & $299(15.5)$ \\
\hline Controlling behaviours & $679(35.2)$ \\
\hline Any IPV in past 12 months & $173(9.0)$ \\
\hline Witnessed parents' IPV & $259(11.5)$ \\
\hline
\end{tabular}

$p<0.001$, sexual OR 16.60 (95\% CI 7.84 - 35.15); $p<0.001$, emotional OR 10.42 (95\% CI $7.81-13.89) ; p<0.001$ ) and recent IPV (OR 8.18 (95\% CI 5.42 - 12.35); $p<0.001)$. Results are shown in Table 2.

\section{Discussion}

The results of this study offer the first national-level insights into IPV in SA women aged $\geq 50$ years. Respondents reported a lifetime prevalence of IPV that is on par with women of reproductive age in SA. Compared with women aged 15 - 49 in the same DHS survey, 


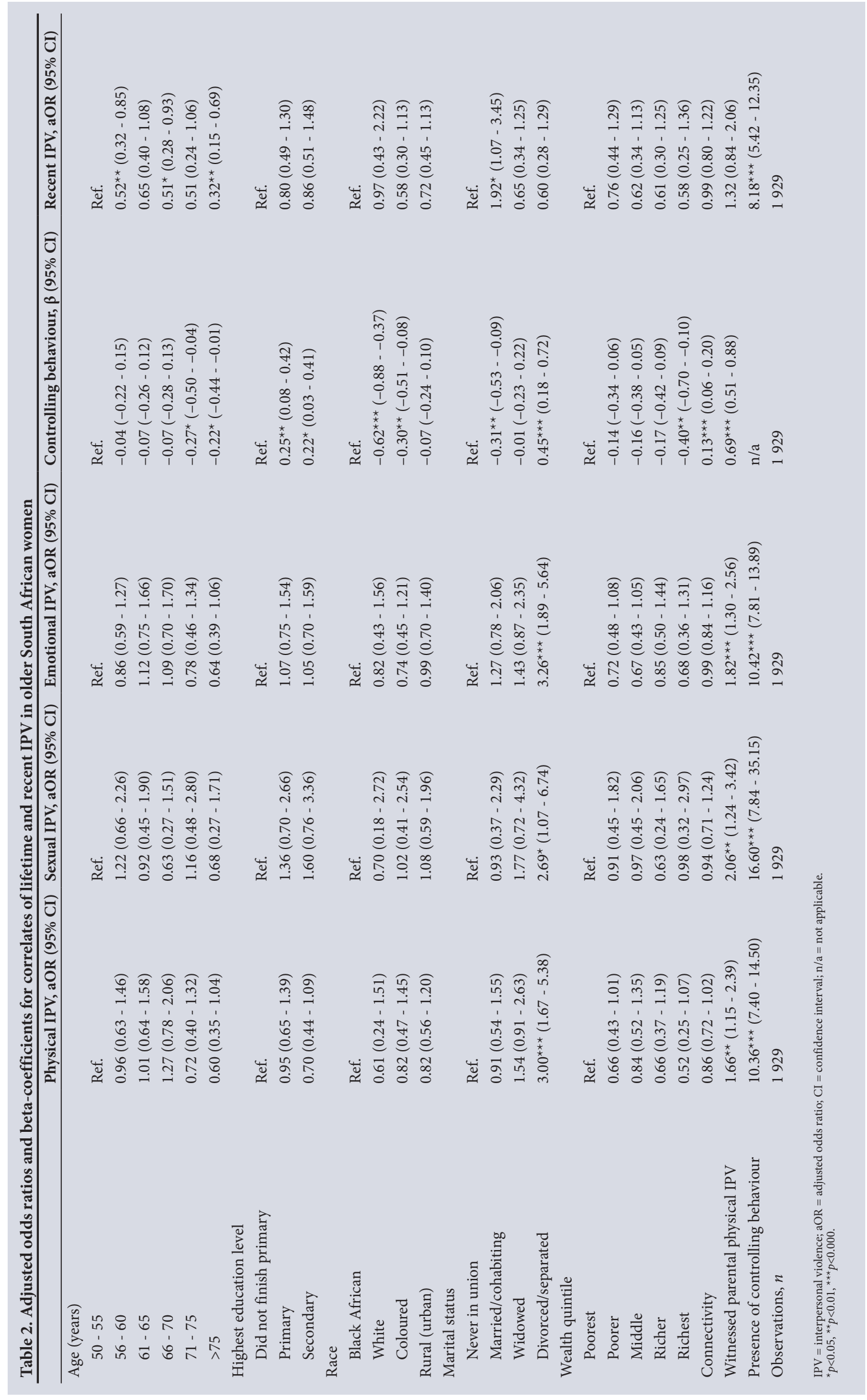


older women reported slightly more physical IPV (15.5\% v. $13.8 \%)$, sexual IPV (4.6\% v. $3.8 \%)$ and emotional IPV (19.7\% v. $18.7 \%)$. None of these differences was statistically significant, however, meaning that the increased prevalence in older women is likely to be an artefact of age. However, nearly 1 in 10 older women (9.0\%) also reported experiencing IPV at least once in the past 12 months, suggesting that IPV continues beyond reproductive age and is a concern in this population.

Results of the multilevel models indicate that while age beyond the reproductive years is not a strong predictor of lifetime experience of IPV, it is associated with recent IPV. Women aged $56-60,66-70$, and $>75$ had significantly lower odds of reporting IPV in the past 12 months, and those in the top two age cohorts were significantly less likely to report controlling behaviour. This supports existing data from the USA ${ }^{[10]}$ and Europe ${ }^{[12]}$ showing that recent IPV decreases in old age. Other correlates of IPV departed from those found throughout the SA literature on women of reproductive age. Level of education was not found to be associated with lifetime or recent IPV, but was associated with an increased likelihood of reporting controlling behaviour, as was increased connectivity in the form of television, radio, mobile phone use and internet access. These results may be due to formal schooling ${ }^{[35,36]}$ and greater access to forms of communication ${ }^{[37,38]}$ providing an entree to more progressive norms regarding gender equality and gender roles. Formal education may also lead to more knowledge of what constitutes controlling behaviour and thus increase rates of reporting (not to be conflated with experiencing) coercive control. Women who do not finish primary school or have low connectivity may therefore indeed experience controlling behaviour, but do not view their partner's behaviour as outside the norm (i.e. 'controlling'). White and coloured/ Indian women reported less controlling behaviour than black African women. Considering the racial divide in educational attainment (especially considering that all women in this sample completed their schooling before the formal end of apartheid in 1994), this finding seems to counter the notion that access to more progressive cultural norms leads to higher reporting of coercive control. Rates of lifetime and recent abuse were not significantly different by race, which departs significantly from the literature on women of reproductive age. ${ }^{[15,39,40]}$ More research is warranted to elucidate the drivers of IPV and coercive control in these different facets of SA society.

Women who were divorced or separated from their partner had about three times the odds of reporting all types of IPV than women who had never been married. While this finding suggests that women in SA may be empowered to leave abusive relationships, it may also indicate that dating violence and other types of IPV experienced outside of formal marriage are under-reported. In another departure from the existing literature on IPV in low- and middle-income contexts, wealth quintile was not a strong predictor of past or recent IPV. While those in the richest quintile reported significantly fewer controlling behaviours than those in the poorest quintile, the inverse dose-response relationship between household wealth and IPV seen in previous studies of women of reproductive age ${ }^{[41-43]}$ is absent in this sample. This finding may reflect the especially high level of income inequality present in SA, with relatively few people in the middle two quintiles. Given our relatively small sample, this finding could represent a type II error.

Even when interviewed at age $\geq 50,11.5 \%$ of women in this sample recalled childhood experiences of witnessing their father physically abuse their mother. The finding that witnessing parental IPV was significantly associated with about twice the odds of lifetime experience of all three types of IPV studied, as well as with reporting significantly more controlling behaviours, underscores the power of this experience on violence throughout the life course and the necessity of primary prevention interventions aimed at families with young children. Finally, a strong relationship between the presence of controlling behaviours and lifetime and recent reports of physical, sexual and emotional IPV is consistent with the broader theoretical and empirical literature on violence against women. Men who feel tied to patriarchal gender roles and norms, or feel insecure in their masculinity, often constrain the autonomy of their partners. ${ }^{[25,44-46]}$ Violence often results when these constraints are challenged either by the female partner or by others in the community. ${ }^{[77,48]}$

\section{Study limitations}

This study has several limitations, and its results should be viewed as a first step towards understanding IPV in older women better across low- and middle-income contexts. First, the DHS is a crosssectional survey, which precludes any causal inference. Longitudinal studies are needed to better understand: (i) how IPV manifests from reproductive age through older age; (ii) how the negative health outcomes of violence experienced at any time in life are experienced beyond the reproductive years; and (iii) how witnessing IPV as a child affects both the experience and perpetration of IPV across the lifespan. Second, the types of IPV studied in the DHS may not be as relevant to older women as they are to women of reproductive age. A pan-European report on IPV in older women found that types of violence not included in the DHS, such as intentional neglect, may be more prevalent in this population. ${ }^{[12]}$ The absence of DHS questions on types of IPV outside the kinds of physical, sexual and emotional violence most often reported by younger women is likely to have led to an underestimate of the prevalence of IPV in older women. Formative, qualitative work should be done to elucidate the types of IPV that are experienced by older South Africans, and these should be included in future quantitative studies. Third, the analysis collapsed categories of some demographic variables such as race and education to improve statistical power. Doing so not only increases the chance of type I and type II error ${ }^{[49]}$ but obscures important information. Future studies should include purposeful sampling to ensure adequate representation from across the racial, ethnic and class groupings in SA.

\section{Conclusions}

This study provides the first glimpse into IPV among older women in SA and demonstrates that it is an important public health concern. Building on this foundation, qualitative studies should focus on the manifestations of IPV in older women, while large-scale quantitative studies such as the DHS should more routinely include women beyond reproductive age. It is also important to ensure that women aged $>50$ years are meaningfully included in the design and implementation of the presidential response to GBV, ensuring that the plan addresses the specific vulnerabilities faced by ageing women. As the country continues its rapid demographic transition, more women will be subject to the confluence of elder abuse and IPV, making it important to continue studying violence and its negative health and social implications in this context.

\section{Declaration. None.}

\section{Acknowledgements. None.}

Author contributions. NM conceptualised the study and completed the analyses. ZE provided additional conceptual development and was integral to situating the significance of the study in the South African context. NM and ZE contributed equally to manuscript development.

Funding. None.

Conflicts of interest. None. 
1. World Health Organization. Global and regional estimates of violence against women: Prevalence and health effects of intimate partner and non-partner sexual violence. 2013. http://apps.who.int/ iris/bitstream/10665/85239/1/9789241564625 eng.pdf (accessed 5 March 2020).

2. McGarry J, Simpson C, Hinchliff-Smith K. The impact of domestic abuse for older women: A review of the literature. Health Soc Care Community $2011 ; 19(1): 3-14$. https://doi.org/10.1111/j.1365 2524.2010.00964.

3. Stöckl H, Penhale B. Intimate partner violence and its association with physical and mental health symptoms among older women in Germany. J Interpers Violence 2015;30(17):3089-3111. https:/ doi.org/10.1177/0886260514554427

4. McGarry J, Bowden D. Unlocking stories: Older women's experiences of intimate partner violence told through creative expression. J Psychiatr Ment Health Nurs 2017;24(8):629-637. https://doi. org $/ 10.1111 /$ jpm.12411

5. World Health Organization. World report on ageing and health 2015. https://www.who.int/ageing/ events/world-report-2015-launch/en/ (accessed 3 March 2020).

6. Pathak N, Dhairyawan R, Tariq S. The experience of intimate partner violence among older women A narrative review. Maturitas 2019;121:63-75. https://doi.org/10.1016/j.maturitas.2018.12.011

7. Mezey NJ, Post LA, Maxwell CD. Redefining intimate partner violence: Women's experiences with physical violence and non-physical abuse by age. Int J Sociol Soc Policy 2002;22(7):122-154. https:// doi.org/10.1108/01443330210790120

8. Poole C, Rietschlin J. Intimate partner victimization among adults aged 60 and older: An analysis of the 1999 and 2004 General Social Survey. J Elder Abuse Neglect 2012;24(2):120-137. https://doi.org/ $10.1080 / 08946566.2011 .646503$

9. Zink T, Fisher BS, Regan S, Pabst S. The prevalence and incidence of intimate partner violence in older women in primary care practices. J Gen Intern Med 2005;20(10):884. https://doi.org/10.1111/ j.1525-1497.2005.0191.x

10. Gerino E, Caldarera AM, Curti L, Brustia P, Rollè L. Intimate partner violence in the golden age: Systematic review of risk and protective factors. Front Psychol 2018:9:1595. https://doi.org/10.3389/ fpsyg.2018.01595

11. Crockett C, Brandl B, Dabby FC. Survivors in the margins: The invisibility of violence against older women. J Elder Abuse Neglect 2015:27(4-5):291-302. https://doi.org/10.1080/08946566.2015.1090361

12. Nägele B, Böhm U, Görgen T, Tóth O. Intimate partner violence against older women - summary report. Summary of a research project carried out in Austria, Germany, Hungary, Poland, Portugal and United Kingdom. December 2010. http://www.ipvow.org/images/ipvow/reports/summary report_final.pdf (accessed 9 September 2020).

13. Simmons B, Baxter JS. Intimate partner violence in older women: What home healthcare clinicians should know. Home Healthcare Now 2010;28(2):82-89. https://doi.org/10.1097/ NHH.0b013e3181cb52a3

14. Beaulaurier RL, Seff LR, Newman FL, Dunlop B. External barriers to help seeking for older women who experience intimate partner violence. J Fam Violence 2007;22(8):747-755. https://dol. org/10.1007/s10896-007-9122-y

15. Abrahams N, Mathews S, Martin LJ, Lombard C, Jewkes R. Intimate partner femicide in South Africa in 1999 and 2009. PLoS Med 2013;10(4):e1001412. https://doi.org/10.1371/journal.pmed.1001412

16. Devries KM, Mak JYT, García-Moreno C, et al. The global prevalence of intimate partner violence against women. Science 2013;340(6140):1527-1528. https://doi.org/10.1126/science.1240937

17. Jewkes R. Intimate partner violence: Causes and prevention. Lancet 2002;359(9315):1423-1429. https://doi.org/10.1016/S0140-6736(02)08357-5

18. Khumalo T. South Africa declares 'femicide' a national crisis. Voice of Africa, 20 September 2019. https://www voanews.com/africa/south-africa-declares-femicide-national-crisis (accessed 6 March 2020)

9. Cohen M, Mbatha A. Ramaphosa vows to tackle gender-based violence in South Africa. Bloomberg News, 5 September 2019. https://www.bloomberg.com/news/articles/2019-09-05/south-africa-sramaphosa-pledges-to-tackle-gender-based-violence (accessed 7 March 2020).

20. Mayosi BM, Flisher AJ, Lalloo UG, Sitas F, Tollman SM, Bradshaw D. The burden of noncommunicable diseases in South Africa. Lancet 2009;374(9693):934-947. https://doi.org/10.1016/ S0140-6736(09)61087-4

21. ICF International. 2016 South Africa Demographic and Health Survey. https://dhsprogram.com/ what-we-do/survey-search.cfm?sendsearch $=1 \&$ YrFrom $=2016 \& \mathrm{YrTo}=2016 \&$ str $1=55, \& \mathrm{crt}=1 \&$ listo that 0 (accessed 10 march 2020$)$

22. ICF International. Demographic and Health Survey Interviewer's Manual. 2012. https://www. dhsprogram.com/pubs/pdf/DHSM1/DHS6_Interviewer_Manual_19Oct2012_DHSM1.pdf (accessed 1 April 2020)

23. ICF International. DHS Phase 6 Questionnaire. 2013. http://dhsprogram.com/What-We-Do Survey-Types/DHS-Questionnaires.cfm (accessed 9 September 2020).

24. ICF International. Wealth Index Construction. 2016. https://dhsprogram.com/topics/wealth-index/ Wealth-Index-Construction.cfm (accessed 9 September 2020).

25. World Health Organization/London School of Hygiene and Tropical Medicine. Preventing intimate partner and sexual violence against women: Taking action and generating evidence. 2010. https:// www.who.int/violence injury prevention/publications/violence/9789241564007 eng.pdf?ua= (accessed 9 September 2020)
26. World Health Organization. Violence against women. 29 November 2017. http://www.who.int/ mediacentre/factsheets/fs239/en/ (accessed 9 September 2020).

27. Cardoso LF, Sorenson SB. Violence against women and household ownership of radios, computers, and phones in 20 countries. Am J Public Health 2017;107(7):1175-1181. https://doi.org/10.2105/ AJPH.2017.303808

28. Xue J, Lin K, Sun IY, Liu J. Information communication technologies and intimate partner violence in China. Int J Offender Ther Comp Criminol 2018;62(16):4904-4922. https://doi. org/10.1177/0306624X18801500

29. Vung ND, Krantz G. Childhood experiences of interparental violence as a risk factor for intimate partner violence: A population-based study from northern Vietnam. J Epidemiol Community Health 2009;63(9):708-714. https://doi.org/10.1136/jech.2008.076968

30. Bandura A, Walters RH. Social Learning Theory. Englewood Cliffs, NJ: Prentice Hall, 1977.

31. Assari S. Multilevel approach to intimate partner violence research and prevention. Int J Prev Med 2013;4(5):616-617

32. Bell BA, Ferron JM, Kromrey JD. Cluster size in multilevel models: The impact of sparse data structures on point and interval estimates in two-level models. JSM proceedings, section on survey research methods, 2008:1122-1129. http://www.asasrms.org/Proceedings/y2008/Files/300933.pdf (accessed 3 April 2020).

33. Stephenson R, Elfstrom KM, Winter A. Community influences on married men's uptake of HIV testing in eight African countries. AIDS Behav 2013;17(7):2352-2366. https://doi.org/10.1007/s10461-0120223-0

34. Steele F, Diamond I, Amin S. Immunization uptake in rural Bangladesh: A multilevel analysis. J R Stat Soc Ser A 1996;159(2):289-299. https://doi.org/10.2307/2983175

35. Wingood GM, DiClemente RJ. Application of the theory of gender and power to examine HIV-related exposures, risk factors, and effective interventions for women. Health Educ Behav 2000;27(5):539-565. https://doi.org/10.1177/109019810002700502

36. Boyle MH, Georgiades K, Cullen J, Racine Y. Community influences on intimate partner violence in India: Women's education, attitudes towards mistreatment and standards of living. Soc Sci Med 2009;69(5):691-697. https://doi.org/10.1016/j.socscimed.2009.06.039

37. Kim J, Pronyk P, Barnett T, Watts C. Exploring the role of economic empowerment in HIV prevention. AIDS 2008;22(Suppl 4):S57-S71. https://doi.org/10.1097/01.aids.0000341777.78876.40

38. Pronyk PM, Hargreaves JR, Kim JC, et al. Effect of a structural intervention for the prevention of intimate-partner violence and HIV in rural South Africa: A cluster randomised trial. Lancet 2006;368(9551):1973-1983. https://doi.org/10.1016/S0140-6736(06)69744-4

39. Dunkle KL, Jewkes R, Nduna M, et al. Perpetration of partner violence and HIV risk behaviour among young men in the rural Eastern Cape, South Africa. AIDS 2006;20(16):2107-2114. https://doi. $\operatorname{org} / 10.1097 / 01$.aids.0000247582.00826.52

40. Dunkle KL, Jewkes R, Brown HC, Gray GE, McIntryre JA, Harlow SD. Gender-based violence, relationship power, and risk of HIV infection in women attending antenatal clinics in South Africa. Lancet 2004;363(9419):1415-1421. https://doi.org/10.1016/S0140-6736(04)16098-4

41. Meiksin R, Meekers D, Thompson S, Hagopian A, Mercer MA. Domestic violence, marital control, and family planning, maternal, and birth outcomes in Timor-Leste. Matern Child Health J 2015;19(6):13381347. https://doi.org/10.1007/s10995-014-1638-1

42. Uthman OA, Lawoko S, Moradi T. Factors associated with attitudes towards intimate partner violence against women: A comparative analysis of 17 sub-Saharan countries. BMC Int Health Hum Rights 2009;9:14. https://doi.org/10.1186/1472-698X-9-14

43. Vyas S, Watts C. How does economic empowerment affect women's risk of intimate partner violence in low and middle income countries? A systematic review of published evidence. J Int Dev 2009:21(5):577-602. https://doi.org/10.1002/jid.1500

44. Hatcher AM, Romito P, Odero M, Bukusi EA, Onono M, Turan JM. Social context and drivers of intimate partner violence in rural Kenya: Implications for the health of pregnant women. Cult Health Sex 2013:15(4):404-419. https://doi.org/10.1080/13691058.2012.760205

45. Santhya KG, Haberland N, Ram F, Sinha RK, Mohanty SK. Consent and coercion: Examining unwanted sex among married young women in India. Int Fam Plann Perspect 2007;33(3):124-132.

46. Arnott CC. Husbands' attitude and wives' commitment to employment. J Marriage Fam 1972:34 (4):673-684. https://doi.org/10.2307/350320

47. Pallitto CC, O'Campo P. Community level effects of gender inequality on intimate partner violence and unintended pregnancy in Colombia: Testing the feminist perspective. Soc Sci Med 2005;60(10):22052216. https://doi.org/10.1016/j.socscimed.2004.10.017

48. Sabarwal S, Santhya KG, Jejeebhoy SJ. Women's autonomy and experience of physical violence within marriage in rural India: Evidence from a prospective study. J Interpers Violence 2014;29(2):332-347. https://doi.org/10.1177/0886260513505144

49. Altman DG, Royston P. The cost of dichotomising continuous variables. BMJ 2006;332(7549):1080. https://doi.org/10.1136/bmj.332.7549.1080

Accepted 17 June 2020. 